\title{
The Mannheim Declaration of Stroke in Eastern Europe
}

\author{
Accepted at the 13th European Stroke Conference, \\ Mannheim-Heidelberg, Germany, May 12-15, 2004
}

Stroke is the most devastating cause of morbidity and mortality in the Eastern European countries. In this region, stroke is more frequent and the victims are younger than in Western Europe. Moreover, the incidence of stroke is significantly higher in social classes with low income, which represents a higher percentage of the Eastern European populations. Stroke is still one of the most important contributors to the mortality gap between East and West. The socioeconomic impact of stroke further weakens the economic development of these societies.

The frequency of stroke is partly dependent on modifiable risk factors. In Eastern Europe, relatively more high-risk patients (hypertension + diabetes + smoking) live in worse environmental conditions compared with Western individuals.

The positive tendency of decreasing mortality and morbidity could not be seen in the majority of Eastern countries, therefore urgent and efficient steps should be done to improve the situation.

To avoid death and permanent disability caused by stroke in Eastern Europe, a specialised action plan has been established. This action plan is based on the Helsingborg Declaration and the 10-Point Action Plan to Tackle Stroke summarised by the European Parliament in June, 2003.

The governments of these countries should elaborate a countryspecific programme based on the following elements.

1 Highlight the link between stroke and risk factors to physicians, emergency medical personnel, other health care professionals and the general public by facilitating education programmes. Recognition of symptoms of stroke is the cornerstone of successful stroke management.

2 Health care budgets should be allocated considering stroke prevention and therapy as a priority.

3 In specialised stroke units, widespread application of diagnostic interventions, pharmacological and surgical treatments should be available for all patients with stroke. The prevention and treatment of stroke should be based on the principle of evidence-based medicine. There is a pressing need for further randomised and placebo-controlled trials.

4 Stroke patients should receive an individual, patient-centred rehabilitation treatment carried out by an interdisciplinary team and involving the family.
5 Ensure the timely prevention of stroke by adequately treated modifiable risk factors such as hypertension, diabetes, hyperlipidaemia and atrial fibrillation by helping physicians making their treatment decisions using swiftly adoptable guidelines.

6 Because stroke is an emergency and efficient therapy is possible only in a limited time window, simplify the transport of acute stroke patients from their home to the stroke units and try to shorten the stroke-to-needle time.

7 Persuade people of the importance of changing their lifestyle including smoking, heavy alcohol and calorie intake, lack of physical activity, mental and emotional stress, which are very common, but also modifiable risk factors of stroke in Eastern Europe.

8 Encourage active and establish new patients' associations. Patient groups play an important role in health policy and are able to coordinate actions to promote better rehabilitation and social support for people with stroke and their families.

9 Set realistic, time-based targets for stroke management and produce population-based monitoring systems covering incidence, prevalence, mortality and disability to provide an Eastern European picture of stroke management.

10 Foundation of an East and West European Stroke Forum to share all information between Western and Eastern European stroke professionals by identifying and disseminating the best practices in stroke prevention and treatment.

Prof. J. Bogousslavsky, Lausanne

Prof. M.G. Hennerici, Mannheim

Prof. M. Kaste, Helsinki

Prof. L. Csiba, Debrecen

Prof. M. Brainin, Maria Gugging

Prof. D. Bereczki, Debrecen

Prof. Z. Nagy, Birmingham

Prof. A. Czlonkowska, Warsaw

Prof. V. Demarin, Zagreb

Prof. J. Pascu, Romania

Prof. V.I. Skvortsova, Moscow

Prof. E. Ehler, Pardubice

\section{KARGER}

(c) 2004 S. Karger AG, Basel

Fax +4161306 1234

E-Mail karger@karger.ch

www. karger.com
Accessible online at: www. karger.com/ced 